\title{
HUBUNGAN ADVERSITY QUOTIENT DAN STRES PADA SISWA KELAS XII YANG AKAN MENGIKUTI UJIAN NASIONA DI SMAN 1 PADANG
}

\author{
Anggawira, Andhika \\ Fakultas Psikologi Universitas Putra Indonesia YPTK Padang \\ anggawira4ever@yahoo.co.uk
}

\begin{abstract}
The study objective was to determine correlation between adversity quotient and stress of $12^{\text {th }}$ grade in senior high school 1 Padang that who will be held on final examination for their graduation. This research used survey method and the analaysis used correlation techniques. Sample Size of 158 obtained by purposive sampling technique. The instrument used was aquestionaire to measure stress by HSCL-25 and adversity quetion by likert scale's Rahmawati (2007). The result shown 65\% students has indicated stress, and $71 \%$ student has middle range on adversity quotient. Result of the hypothesist namely there is negative correlation between adversity quotient and stres but they don't have enough significant's value.
\end{abstract}

Keyword : Adversity Quotient, Stres, Senir High School Student, National Examination

\begin{abstract}
ABSTRAK
Penelitian ini bertujuan untuk mengetahui hubungan antara adversity quotient and stres pada siswa kelas XII yang akan mengikuti ujian nasional di SMAN 1 Padang. Metode Penelitian dilakukan dengan survey. Teknik analisis data menggunakan teknik korelasi ganda.. Pengambilan sample sejumlah 158Pengukuran stres dilakukan dengan menggunakan skala HSCL-25 dan penggunaan skala Adversity Quotient digunakan dengan menggunakan skala likert yang disusun oleh Rahmawati (2007). Hasil Pengukuran menunjukkan bahwa $65 \%$ dari siswa SMAN 1 Padang kelas XII yang akan mengikuti ujian nasional menunjukkan indikasi mengalami stres, sedangkan pengukuran tingkat AQ menunjukkan $71 \%$ siswa SMA 1 Padang kelas XII yang akan mengikuti ujian nasional berada pada kategori sedang. Hasil uji hipotesis menunjukkan bahwa Adversity Quotient dan Stres memiliki hubungan yang berlawanan namun hubungan tersebut tidak memiliki nilai signigfikansi yang cukup.
\end{abstract}

Kata Kunci : Adverstiy Quotient, Stres, Siswa SMA, Ujian Nasional

\section{PENDAHULUAN}

Dalam kehidupan manusia tidak akan pernah lepas dari dunia pendidikan, baik pendidikan formal yang didapat di sekolah-sekolah maupun pendidikan non formal yang didapat di luar sekolah. Dalam UU Nomor 20 tahun 2003 Pasal 3 tentang sistem pendidikan nasional disebutkan bahwa tujuan pendidikan nasional adalah mengembangkan potensi peserta didik agar menjadi manusia yang beriman dan bertakwa kepada Tuhan Yang Maha Esa, berakhlak mulia, sehat, berilmu, cakap, kreatif, mandiri dan menjadi warga negara yanng demokratis serta bertanggung jawab.

Ujian kelulusan yang diadakan secara nasional atau biasa disebut dengan Ujian Nasional merupakan sebuah evaluasi pembelajaran yang didapat oleh setiap siswa mulai dari tingkat dasar (SD sederajat), menengah pertama (SMP sederajat) ataupun menengah atas/kejuruaan 
(SMA/SMK sederajat). Hasil evaluasi inilah yang menentukan apakah siswa/i dapat melanjutkan pendidikan ke tahapan selanjutnya atau tidak. Seperti yang terjadi pada SMA N 1 Padang, yang mana juga menyelenggarakan Ujian Nasional untuk evaluasi pembelajaran yang didapat oleh siswa mereka.

Fungsi ujian nasional yang memutuskan kelulusan/ketidaklulusan siswa menimbulkan dampak psikologis berupa kekhawatiran, kecemasan dan ketakutan akan kegagalan, yang kesemua nya merupakan bentuk-bentuk reaksi psikologis dari kondisi Stres.

Menurut Arjanto (2016), pada awalnya dengan adanya persiapan Ujian Nasional membuat stres yang timbul memiliki dampak positif dengan munculnya semangat untuk terus belajar dengan baik, namun pada tahapan selanjutnya mulai muncul keluhan dari siswa berupa mengantuk di kelas, karena kurangnya jam istirahat dan disertai dengan tumpukan tugas yang semakin hari semakin dirasakan sulit untuk diselesaikan sehingga akhirnya para siswa merasakan kelelahan dan kecapaian. Ketika hal ini terus terjadi, dapat mengakibatkan peserta didik menjadi cemas, gugup, was-was, menurunnya konsentrasi, sering berkeringat dingin tanpa sebab, gangguan tidur, gemetaran sampai ada yang mengalami pingsan. Gangguan-gangguan lainnya yang dapat saja terjadi pada peserta didik adalah mengalami sakit perut, jantung berdebar-debar, takut tidak lulus. Timbulnya faktor tersebut yang merupakan gejala gangguan stres dilatar belakangi oleh persiapan yang menguras energi fisik, tuntutan orang tua untuk memperoleh nilai prestasi tinggi dan rasa kurang percaya diri.

Kondisi Stres yang dialami oleh siswa kelas XII saat menghadapi Ujian Nasional membuat mereka harus menghadapinya, agar ia bisa lulus untuk bisa memenuhi harapan guru dan kedua orang tuanya. Kemampuan siswa dalam menghadapi Stres dipengaruhi oleh selfconcept, self-esteem, locus of control dan coping strategy.

Kemampuan seseorang dalam menghadapi Stres dan kesulitan dalam hidupnya dengan baik oleh Paul G. Stoltz (2007) dinyatakan sebagai Adversity Quotient. Adversity Quotient memiliki pengaruh yang sangat besar dalam mengadapi kegagalan, kondisi-kondisi sulit, dan tekanan.

Dengan Adversity Quotient, seseorang tidak hanya dapat menghadapi kondisi sulit dan kegagalan namun juga dapat mengubahnya menjadi peluang untuk meraih kesuksesan yang lebih besar.Kondisi Stres yang dialami oleh siswa dapat diminimalisir jika siswa tersebut memiliki Adversity Quotient yang tinggi. Hal ini membuat siswa selain memiliki motivasi berprestasi yang cukup dan dapat mencapai tujuannya dalam Ujian Nasional.

Dari uraian di atas, peneliti berkeinginan untuk mengetahui hubungan antara adversity quotient dan stres pada siswa kelas XII SMAN 1 Padang yang akan mengikuti ujian Nasional

\section{TINJAUAN LITERATUR}

\subsection{Stres}

\subsubsection{Pengertian Stres}

Lazarus (dalam Lahey, 2009) mengatakan bahwa Stres dapat diartikan sebagai kesenjangan antara tuntutan lingkungan dan kemampuan individu untuk menangani tuntutan lingkungan atau situasi tersebut. Stres dapat diartikan sebagai respon psikologis yang berdampak pada fisik, emosi maupun hubungan sosial disebabkan adanya situasi menekan.

Sarafino (2006) mendefinisikan stres adalah kondisi yang disebabkan oleh adanya interaksi antara individu dengan lingkungan, yang menimbulkan tuntutan - tuntutan, yang berasal dari situasi yang bersumber pada sistem biologis, psikologis dan sosial dari seseorang. Stres Merupakan sebuah tekanan internal maupun eksternal serta kondisi bermasalah lainnya dalam kehidupan

Gaol (2016) menyebutkan pengertian stres dari 3 pendekatan teori :

1) Stres model stimulus 
Stres adalah sebuah stimulus yang dianggap mengancam atau membahayakan

2) Stres model respons

Stres adalah respon saat tubuh bereaksi terhadap sumber-sumber stres

3) Stres model transaksional

Stres adalah suatu kondisi saat adanya proses pengevaluasian dari sumber stres yang terjadi

\subsubsection{Jenis- Jenis Stres}

Berdasarkan dampaknya stres tidak hanya memberikan dampak negatif bagi manusia, tapi juga bisa memberikan dampak positif. Stres yang memberikan dampak positif disebut dengan. Stres berdampak positif disebut dengan eustres, sedangkan stres berdampak negatif disebut dengan distres (Gadzella, Baloglu, Masten dan Wang, 2012), Ketika eustres terjadi, maka terjadilah peningkatan kinerja dan kesehatan, akan tetapi sebaliknya jika seseorang mengalami distres maka mengakibatkan semakin buruknya kinerja, kesehatan dan bahkan sampai mengganggu hubungan sosial dengan orang lain. (Gaol, 2016) atian.

\subsubsection{Gejala-Gejala stres}

Menurut Hadjana (dalam Sukoco, 2014), seseorang yang mengalami stres memiliki gejala-gejala sebagai berikut

A. Gejala Fisikal, yaitu gejala yang berkaitan dengan kondisi fisik dan fungsi fisik seseorang

B. Gejala Emosi, yaitu gejala stres yang berkaitan dengan kondisi psikis atau mental seseorang

C. Gejala Intelektual, yaitu gejala stres yang berkaitan dengan kondisi pikiran seseorang

D. Gejala Interpersonal,

Yaitu gejala yang berkaitan dengan hubungan dengan orang lain.

\subsection{Adversity Quotient}

\subsubsection{Pengertian Adversity Quotient}

Adversity Quotient menurut Paul Stoltz (2007) adalah kemampuan seseorang dalam menghadapi permasalahan dan stres dalam hidupnya. Adversity Quotient memiliki pengaruh hyang sangat besar dalam diri seseorang menghadapi permasalahn hidupnya.

Stoltz (2007) mendefinisikan adversity quotient (AQ) dalam tiga bentuk: pertama, adversity quotient sebagai konsep kerangka kerja yang baru dalam memahami dan mempertinggi semua bagian dalam kesuksesan. Kedua, adversity quotient adalah suatu pengukuran tentang bagaimana seseorang merespon terhadap kesulitan. Ketiga, adversity quotient sebagai alat yang didasarkan pada penelitian ilmiah untuk meningkatkan kemampuan seseorang dalam merespon terhadap suatu kesulitan.

\subsubsection{Dimensi dalam Adversity Quotient}

Stoltz menyebutkan bahwa Adverstiy Quotient memiliki kemampuan yang teridir dari 4 (empat) dimensi, yaitu :

\section{A. Control (Kendali Diri)}

Dimensi merupakan kendali seseorang untuk merasakan terhadap sebuah peristiwa yang menimbulkan kesulitan dalam hidupnya.

\section{B. Origin and Ownership}

Dimensi Origin meupakan bagaimana proses individu mengakui siapa atau apa yang menjadi asal usul kesulitan dan sampai sejauh mana individu mengakui akibat-akibat dari kesulitan itu.

Dimensi Ownership merupakan sebuah dimensi yang berkaitan dengan aspek tanggungjawab individu saat kesulitan tersebut terjadi

C. Reach

Dimensi Reach merupakan sebuah dimensi yang berkaitan dengan aspek sejauh mana kesulitan terjadi dalam kehidupan individu

D. Endurance 
Dimensi Endurance merupakan sebuah dimensi yang berkaitan dengan perkiraan individu terhadap duras waktu kesulitan dan penyebab kesulitan tersebut terjadi

\section{METODOLOGI}

\subsection{Desain Penelitian}

Rancangan dalam penelitian ini adalah cross sectional yaitu untuk mengetahui Hubungan antara Adversity Quotient dan Stres pada siswa SMA kelas XII SMAN 1 Padang yang akan mengikuti Ujian Nasional

\subsection{Waktu dan Tempat Penelitian}

\subsubsection{Waktu}

Penelitian ini di laksanakan pada bulan Januari 2019

\subsubsection{Tempat Penelitian}

Penelitian di laksanakan di SMAN 1 Padang

\subsection{Populasi dan Sampel}

\subsubsection{Populasi}

Populasi dalam penelitian ini adalah seluruh siswa kelas XII SMAN 1 Padang

\subsubsection{Sampel}

Teknik pengambilan sampel dari penelitian ini menggunakan purposive sampling

\subsection{Instrumen Penelitian}

Instrumen dalam penelitian ini menggunakan lembar kuesioner dan check list. Untuk mengetahui adanya indikasi stres digunakan skala HSCL-25.

Untuk mengetahui adanya indikasi stres pada diri seseorang, indikasi stres yang ada pada diri seseorang dalam skala HSCL-25 jika angka tersebut berada lebih besar atau sama dengan 1.75 .

Untuk mengetahui tingkat adverstiy quotient digunakan skala likert yang terdiri dari komponen pada pertanyaan favourable Sangat tidak setuju nilai skornya 1, tidak setuju nilai skornya 2, Setuju nilai skornya 3, Sangat setuju nilai skornya 4. Pada komponen pertanyaan unfavourable maka skor pada penilaian Sangat Setuju (SS) 1, Setuju 2, Tidak Setuju 3, Sangat tidak setuju 4. Skala yang digunakan dalam penelitian ini adalah skala yang telah disusun oleh Renda (2010).

\subsection{Pengumpulan Data}

Data yang di kumpulkan adalah data primer yang di peroleh langsung dari responden.

\section{HASIL DAN PEMBAHASAN}

\subsection{Hasil Analisa Statistik}

Tabel 4.1 Distribusi Frekuensi Indikasi Stres pada siswa kelas XII SMAN 1 Padang

\begin{tabular}{ccc}
\hline Angka Indikator & $\mathbf{N}$ & Persentase (\%) \\
\hline 1-1,74 & 52 & 32,91 \\
Besar atau sama dengan 1,75 & 106 & 67,09 \\
\hline Jumlah & $\mathbf{1 5 8}$ & $\mathbf{1 0 0}$ \\
\hline
\end{tabular}

Tabel 4.2 Distribusi Frekuensi Adversity Quotient (AQ) pada siswa kelas XII SMAN 1 Padang

\begin{tabular}{cccc}
\hline Tingkat AQ & Indikator & N & Persentase (\%) \\
\hline Rendah & $1-109$ & 22 & 13,92 \\
Sedang & $110-119$ & 112 & 70,89 \\
Tinggi & Besar dari 119 & $\mathbf{2 4}$ & 15,19 \\
\hline Jumlah & & $\mathbf{1 5 8}$ & $\mathbf{1 0 0}$ \\
\hline
\end{tabular}


Tabel 4.3 Distribusi Frekuensi AQ Dimensi Control (C) pada siswa kelas XII SMAN 1 Padang

\begin{tabular}{cccc}
\hline Tingkat AQ & Indikator & N & Persentase (\%) \\
\hline Rendah & $1-29$ & 20 & 12,66 \\
Sedang & $30-34$ & 122 & 77,21 \\
Tinggi & Besar dari 34 & 16 & 10,13 \\
\hline Jumlah & & $\mathbf{1 5 8}$ & $\mathbf{1 0 0}$ \\
\hline
\end{tabular}

Tabel 4.5 Distribusi Frekuensi AQ Dimensi Origin dan Ownership (02) pada siswa kelas XII SMAN 1 Padang

\begin{tabular}{cccc}
\hline Tingkat AQ & Indikator & N & Persentase (\%) \\
\hline Rendah & $1-22$ & 20 & 12,66 \\
Sedang & $23-25$ & 100 & 63,29 \\
Tinggi & Besar dari 25 & 38 & 24,05 \\
\hline Jumlah & & $\mathbf{1 5 8}$ & $\mathbf{1 0 0}$ \\
\hline
\end{tabular}

Tabel 4.6 Distribusi Frekuensi AQ DimensiReach (R) pada siswa kelas XII SMAN 1 Padang

\begin{tabular}{cccc}
\hline Tingkat AQ & Indikator & $\mathbf{N}$ & Persentase (\%) \\
\hline Rendah & $1-28$ & 17 & 10,76 \\
Sedang & $29-33$ & 121 & 76,58 \\
Tinggi & Besar dari 33 & 20 & 12,66 \\
\hline Jumlah & & $\mathbf{1 5 8}$ & $\mathbf{1 0 0}$ \\
\hline
\end{tabular}

Tabel 4.7 Distribusi Frekuensi AQ DimensiReach (R) pada siswa kelas XII SMAN 1 Padang

\begin{tabular}{cccc}
\hline Tingkat AQ & Indikator & N & Persentase (\%) \\
\hline Rendah & $1-24$ & 25 & 15.82 \\
Sedang & $25-29$ & 104 & 65.82 \\
Tinggi & besar dari 29 & 29 & 18.36 \\
\hline Jumlah & & $\mathbf{1 5 8}$ & $\mathbf{1 0 0}$ \\
\hline
\end{tabular}

\subsubsection{Hasil Analisa Korelasi dan uji hipotesa}

Tabel 4.8 Hasil Analisa Korelasi dan Uji HipotesA

\begin{tabular}{|c|c|c|c|l|}
\hline $\mathrm{P}$ & $(\alpha)$ & $\begin{array}{c}\text { Nilai Korelasi } \\
(\mathrm{r})\end{array}$ & $\begin{array}{l}\mathrm{R} \\
\text { squared }\end{array}$ & \multicolumn{1}{|c|}{ Kesimpulan } \\
\hline 0,143 & 0.01 & $-0,117$ & 0,014 & sig (2-tailed) $0,143>$ \\
& & & $\begin{array}{l}0,01 \text { level of } \\
\text { significant ( }), \\
\text { berarti H0 diterima }\end{array}$ \\
\hline
\end{tabular}

\section{KESIMPULAN}

Berdasarkan penelitian yang telah di lakukan di SMA 1 Padang, dapat di simpulkan sebagai berikut,

a. Dengan menggunakan angka indikator besar atau sama dengan 1.75 untuk angka yang menunjukkan indikasi stres pada skala HSCL 25, maka jumlah siswa yang menunjukkan indikasi terjadinya stres adalah sebesar 106 orang (67.09\%)

b. Pada skala AQ, frekuensi terbanyak siswa berada pada kategori sedang yaitu sebesar 112 orang $(70,89 \%)$

c. Pada skala AQ dimensi C, frekuensi terbanyak siswa berada pada kategori sedang yaitu sebesar 122 orang $(77,22 \%)$ 
d. Pada skala AQ dimensi O2, frekuensi terbanyak siswa berada pada kategori sedang yaitu sebesar $100(63,29 \%)$

e. Pada skala AQ dimensi R, frekuensi terbanyak siswa berada pada kategori sedang yaitu sebesar $121(76,58 \%)$

f. Pada skala AQ dimensi E, frekuensi terbanyak siswa berada pada kategori sedang yaitu sebesar 104(65,82\%)

g. Pada uji hipotesa didapat nilai $\mathrm{P}=0,143$. $(0,143>0,01)$ artinya adalah Antara adversity Quotient dengan Stres memiliki hubungan, namun tidak signifikan

h. Pada uji nilai korelasi didapat nilai $-0,117$ artinya adalah antara adversity quotient memiliki hubungan negatif dengan stres.

\section{Referensi}

Arjanto, Paul. 2016. Identifikasi Tingkat Stres Peserta Didik Menjelang Ujian Nasional Pada Jenjang Pendidikan Menengah. Jurnal Konseling Indonesia, April 2016 Vol. 1 No. 2.

Gadzella, B.M., Baloglu., M., Masten, W.G., \& Wang, Q. (2012). Evaluation of the student life stres inventory revised. Journal od Instructional Psychology.

Gaol, Nasib Tua Lumban. 2016. Teori Stres : Stimulus, Respon dan Transaksional. Buletin Psikologi 2016 Vol. 24 No. 1

Peraturan Menteri Pendidikan Nasional No. 77 tahun 2008

Renda, Tricahya Frederikus. (2010). Hubungan Antara Adversity Quotient dan Stres pada Mahasiswa yang Bekerja. Skripsi. Yogyakarta: Universitas Sanata Dharma.

Stoltz, Paul G. (2007). Adversity Quotient : Mengubah hambatan menjadi peluang. Alih Bahasa : Hermaya. Jakarta : Grasindo

Sandanger, I., Moum, T., Ingerbrightsen, G., Sorensen, T., Dalgard, O.S., \& Bruusgaard, D. (1999). The meaning and significance of caseness: the hopkins symptom checklist-25 and the composite international diagnostic interview ii. Soc Psychiatry Epidemiol, 34, 53-59.

Sarafino, E. P. (2006). Health psychology :biopsychosocial interactions. New York: John Wiley \& Sons.

Sugiyono. (2014). Metode Penelitian Kuantitati, Kualitatif dan R \& D. Bandung: Penerbit Alfabeta.

Suryabrata Sumadi. (2010). Metodologi Penelitian. Jakarta: Rajawali Pers 